Article

\title{
Deployment of a Bidirectional MW-Level Electric-Vehicle Extreme Fast Charging Station Enabled by High-Voltage SiC and Intelligent Control
}

\author{
Ziwei Liang $₫$, Daniel Merced $₫$, Mojtaba Jalalpour and Hua Bai * \\ Department of Electrical Engineering and Computer Science, University of Tennessee, Knoxville, TN 37996, \\ USA; zliang7@vols.utk.edu (Z.L.); dmercedc@vols.utk.edu (D.M.); mjalalp1@vols.utk.edu (M.J.) \\ * Correspondence: hbai2@utk.edu
}

Received: 24 March 2020; Accepted: 7 April 2020; Published: 10 April 2020

check for updates

\begin{abstract}
Considering the fact that electric vehicle battery charging based on the current charging station is time-consuming, the charging technology needs to improve in order to increase charging speed, which could reduce range anxiety and benefit the user experience of electric vehicle (EV). For this reason, a $1 \mathrm{MW}$ battery charging station is presented in this paper to eliminate the drawbacks of utilizing the normal $480 \mathrm{VAC}$ as the system input to supply the $1 \mathrm{MW}$ power, such as the low power density caused by the large volume of the $60 \mathrm{~Hz}$ transformer and the low efficiency caused by the high current. The proposed system utilizes the grid input of single-phase $8 \mathrm{kVAC}$ and is capable of charging two electric vehicles with $500 \mathrm{~kW}$ each, at the same time. Therefore, this paper details how high-voltage SiC power modules are the key enabler technology, as well as the selection of a resonant-type input-series, output-parallel circuitry candidate to secure high power density and efficiency, while intelligently dealing with the transient processes, e.g., pre-charging process and power balancing among modules, and considering the impact on the grid, are both of importance.
\end{abstract}

Keywords: silicon carbide; extreme fast charging; DC transformer; electric vehicle

\section{Technical Challenges of EV Extreme Fast Charging Stations}

Transportation is revolutionizing as the world welcomes the benefits of electric transportation. The growing interest in electric vehicle (EV) technology is due to their minimum fuel emissions and air pollution. The demand for this kind of vehicles is growing, and the rate of this growth is also expected to increase in the forthcoming years [1,2]. However, there are concerns to be addressed in this regard, including time of charge, range anxiety, cost of charging, and negative impact of charging demand on the grid. Range anxiety and time of charge are the issues that have been addressed in recent years through developing EV fast chargers. Sixteen hours are needed for level-1 chargers, while only 10 minutes are needed for extreme fast chargers (XFCs). This by itself shows how the charging process can impact the adoption of plug-in hybrid electric vehicles. The concept of a gas-station-like experience for charging EVs has become a reality in recent years due to the advancement of XFCs [3,4], e.g., chargers rated at $400 \mathrm{~kW}$ and above. The focus of this work is to design a $1 \mathrm{MW}$ XFC station for two EVs, i.e., $500 \mathrm{~kW}$ per car. Take Tesla Model S as an example, which has $75 \mathrm{kWh}$ battery pack. If the state-of-charge (SOC) window is $80 \%$, a $500 \mathrm{~kW}$ XFC is then able to charge an EV within $75 \mathrm{kWh} \times$ $80 \% / 500 \mathrm{~kW}=7 \mathrm{~m}$, presuming the charging loss is ignorable.

While the majority of EV fast charging stations in the United States have a grid connection of three-phase 480 VAC, which is rectified into a DC bus (normally between 600 VDC and 800 VDC), followed by a DC/DC converter with galvanic isolation. Using such an approach to provide $1 \mathrm{MW}$ sees a challenge from high grid current, which in turn challenges the 480 VAC transformer design. 
As shown in Table 1, the traditional $500 \mathrm{kVA}$ XFC uses a grid transformer of more than $5000 \mathrm{~L}$ and more than $2000 \mathrm{~kg}$. To enhance the system power density and reduce cost, elimination of such bulky and heavy grid transformers is a must [5].

Table 1. Comparison of Metrics for a Traditional and Proposed 500 kVA Fast Charging System.

\begin{tabular}{|c|c|c|}
\hline Figures of Merit & Traditional 500 kVA System & HV SiC Enabled 500 kVA System \\
\hline Power losses $(\% / \mathrm{kW})$ & $\begin{array}{c}\eta=\eta_{\text {xfmr }} \times \eta_{\text {fast charger }}=94.38 \% @ \\
\text { rated power } \\
P_{\text {losses }}=28.09 \mathrm{~kW}\end{array}$ & $\begin{array}{c}\eta \geq 97.75 \% @ \text { rated power } \\
P_{\text {losses }} \leq 11.25 \mathrm{~kW} \\
\eta \geq 95 \% @ 5 \% \text { rated power } \\
P_{\text {losses }} \leq 1.25 \mathrm{~kW}\end{array}$ \\
\hline Size-footprint (dm) & Area $_{\text {total }}=3.5 \mathrm{~m}^{2}$ & Area $_{\text {total }} \leq 0.875 \mathrm{~m}^{2}$ \\
\hline Size-form factor $\left(\mathrm{dm}^{3}\right)$ & $\mathrm{V}_{\text {total }}=5190$ liters & $\mathrm{V}_{\text {total }} \leq 1298$ liters \\
\hline Weight (kg) & $\mathrm{W}_{\text {total }}=3537 \mathrm{~kg}$ & $\mathrm{~W}_{\text {total }} \leq 530 \mathrm{~kg}$ \\
\hline Specific Power & $0.14 \mathrm{kVA} / \mathrm{kg}$ & $>5 \mathrm{kVA} / \mathrm{kg}$ \\
\hline Power Density & $0.09 \mathrm{kVA} / \mathrm{L}$ & $>9.2 \mathrm{kVA} / \mathrm{L}$ \\
\hline Cooling Method & Air Cooled/Oil Filled & Liquid Cooled \\
\hline MTTF (Targets) & $\begin{array}{c}68,960 \mathrm{~h}(7.9 \text { years }) \\
(\text { PFC + DCX) }\end{array}$ & $\begin{array}{c}75,856 \text { h (8.66 years) } \\
\text { (PFC + DCX) }\end{array}$ \\
\hline
\end{tabular}

Recently, wide-bandgap (WBG) semiconductor devices have played a role in developing EV chargers [6,7], not only increasing the power density thanks to the higher switching frequency than $\mathrm{Si}$, but also undertaking higher input voltage, such as $6.5 \mathrm{kV}$ silicon carbide (SiC). This potentially allows the medium voltage (MV) transmission lines (2.4-13.4 kVAC) directly to come into the charging station, thereby saving the 480 VAC step-down grid transformers. As compared in Table 1, elimination of the grid transformer can significantly reduce the size and weight of the overall XFC system. Even though the DC/DC converter such as dual active bridge (DAB) and resonant circuits (LLC and CLLC) all need transformers [8-10], such transformers can be operated at a much higher switching frequency, thereby seeing less weight and size penalty while maintaining galvanic isolation.

From Table 1, we can find that the overall efficiency of the proposed $500 \mathrm{kVA}$ system based on the HV SiC switches is improved by 3\%. The main reasons for the higher efficiency of the proposed system are as follows. 1) The normal input grid voltage of the traditional $500 \mathrm{kVA}$ system is three-phase $480 \mathrm{VAC}$, and the input grid voltage of the proposed $500 \mathrm{kVA}$ system is single-phase $8 \mathrm{kVAC}$, which is more than 17 times that of the traditional system. Given the same power level, higher voltage means lower current, which is beneficial to reduce the power loss of the whole transmission and improve system efficiency. 2) Enabled by $6.5 \mathrm{kV}$ high voltage $\mathrm{SiC}$ power modules, the proposed system will connect to MV transmission lines (2.4-13.4 kVAC), thereby directly saving the $480 \mathrm{VAC}$ step-down grid transformers. Therefore, the large power loss of the $60 \mathrm{~Hz}$ transformer is eliminated, which helps to achieve the higher efficiency. Additionally, a bidirectional feature is highly demanded, especially when there is a grid outage.

With the above consideration and enabled by high voltage (HV) SiC power modules, an approach shown in Figure 1 is proposed. The input $8 \mathrm{kVAC}$ was split evenly among three H-bridge modules, which act as the power factor controller. The AC is then rectified into $4.3 \mathrm{kVDC}$, which is forwarded to a resonant-type DC transformer circuit (DCX) made of a primary half-bridge, a three-winding transformer, and two low-voltage $\mathrm{H}$-bridge paralleled to output $1.3 \mathrm{kVDC}$. Note that this allows the two low-voltage DC (LVDC) buses to be isolated, thereby charging two cars in an isolated manner. The outputs of each of the DCX modules are connected in a parallel output to generate $1 \mathrm{MW}$ power. Each LVDC bus then is connected to a $500 \mathrm{~kW}$ buck converter to charge one EV, as shown in Figure $1 \mathrm{~b}$. 


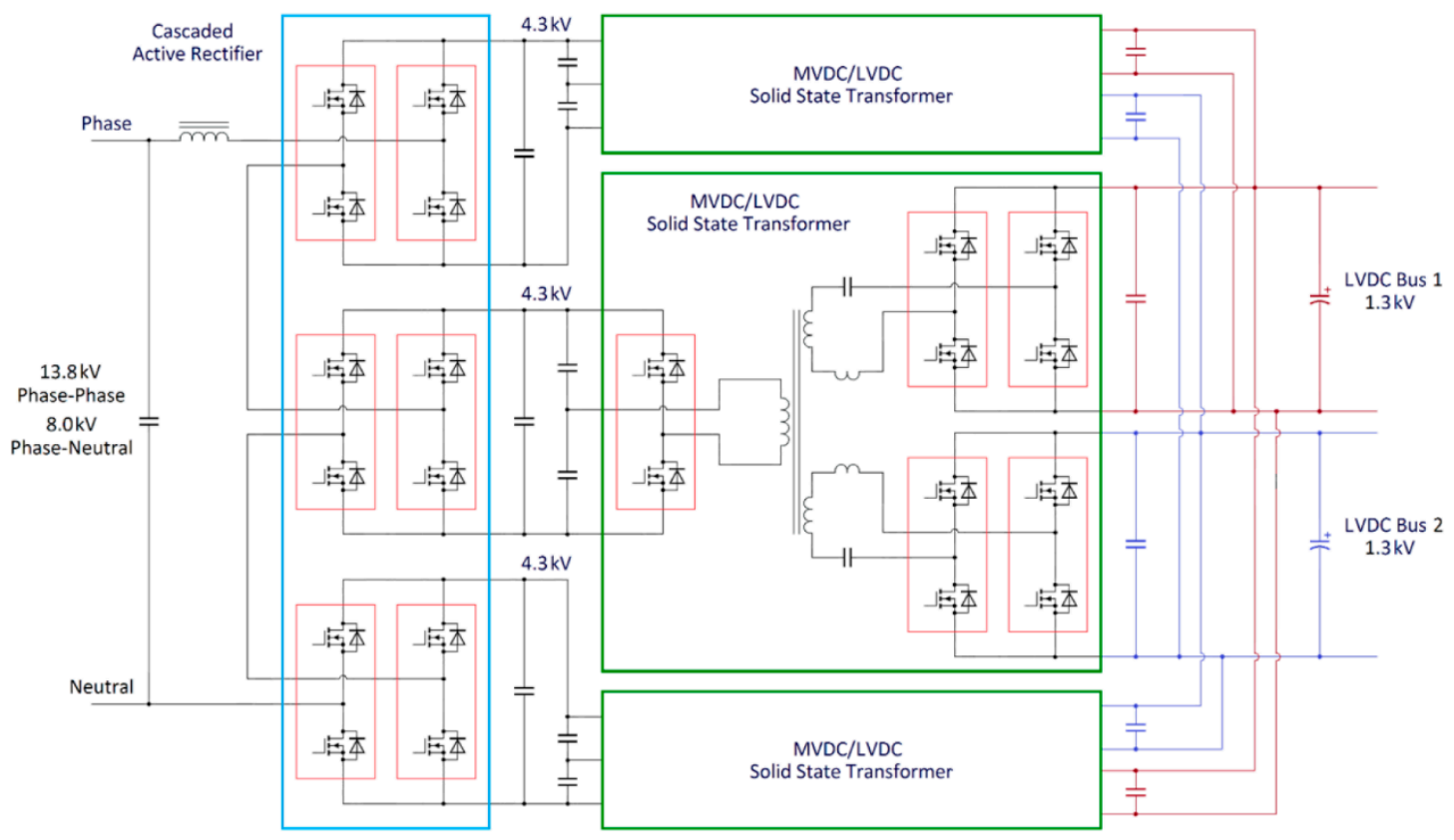

(a)

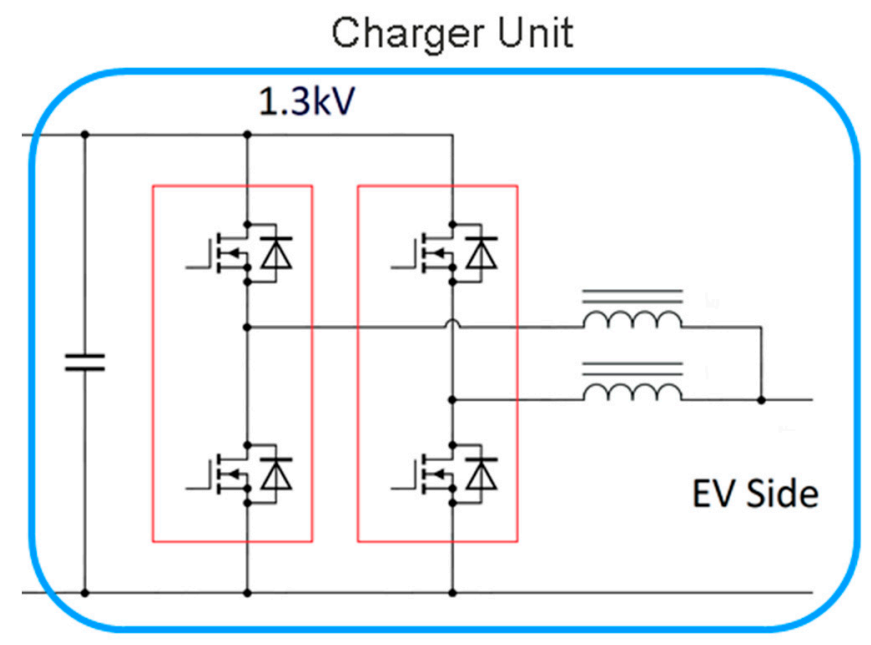

(b)

Figure 1. (a) Block Diagram of proposed design of electric vehicle (EV) extreme fast charger (XFC) station for two vehicles. (b) Block diagram of the following $500 \mathrm{~kW}$ DC/DC converter.

Essentially, such an input-series, output-parallel (ISOP) design successfully eliminates the $480 \mathrm{VAC} / 60 \mathrm{~Hz}$ transformer, while it also realizes bidirectional power flow. Such an ISOP system, however, brings other challenges. 1) Device electrical ratings. With $8 \mathrm{kVAC}$ single-phase grid, the grid connection of each power factor correction (PFC) module is desired to be at $2.6 \mathrm{kVAC}$, which is further boosted to $4.3 \mathrm{kVDC}$. For a $1 \mathrm{MW}$ charging capability, each DC/DC converter module undertakes $333 \mathrm{~kW}$. Selecting the right topology to minimize electrical stress of the switches is key to the success, especially for the DC/DC stage. A detailed comparison of various DC/DC topologies is shown in Table 2, including DAB, DCX, and CLLC. These topologies were chosen because they all provide isolated bidirectional DC/DC conversion by means of a high-frequency transformer and are all widely used [8-12]. As seen in Table 2, even though the peak current and root mean square( RMS) current are high with the DCX converter, the maximum switching off current is close to 0 . This is because the DCX topology always operates at the resonant frequency, which is the main reason this paper selects such topology. All $\mathrm{SiC}$ devices are switched at $30 \mathrm{kHz}$ in all compared topologies. 
Table 2. DCX topology comparison.

\begin{tabular}{llll}
\hline \multicolumn{1}{c}{ Parameter } & \multicolumn{1}{c}{ DAB } & \multicolumn{1}{c}{ CLLC } & \multicolumn{1}{c}{ DCX } \\
\hline Peak Current [A] & 112 & 275 & 250 \\
RMS Current [A] & 93 & 193 & 170 \\
Maximum Switching-off Current [A] & 112 & 154 & 15 \\
C $_{\text {DC }}$ (DC-bus cap between PFC and DCDC [mF]) & 0.8 & 0.6 & 0.01 \\
C $_{\text {out }}($ DC-bus cap at output [mF]) & 0.085 & 0.085 & $1 \times 2$ \\
C $_{\mathrm{r}}$ (resonant cap [ $\left.\left.\mu \mathrm{FF}\right]\right)$ & N/A & 0.316 & 12.665 \\
Transformer $[\mathrm{kVA}]$ & 420 & 423 & 592 \\
\hline
\end{tabular}

The electric stress is then shifted to the resonant circuit and MV transformer. The PFC stage also needs to realize unity power factor and reduce total harmonic distortion (THD), and given the input series structure of the PFCs, the interleaved gate signal is supplied to the PFCs to achieve much smaller current ripple, which could help to reduce the demand of the large bulky DC bus capacitor. This is of importance when reducing the dimensions and cost of the system and improving the power density of the system. Besides, the smart output voltage balancing control is proposed to make sure the three PFC modules have balanced output voltage even under the different load conditions. The balanced output could ensure the same voltage stress among different modules, which is beneficial to the safe operation of the system. This part will be discussed further in Section 2. The DCX topology steps down $4.3 \mathrm{kVDC}$ to a level of $\sim 1.3 \mathrm{kVDC}$. Considering the importance of the resonance of the DCX, the intelligent resonant frequency tracking method based on the master-slave control is proposed. This control method could adjust the working frequency automatically to reach the resonant frequency, and the master-slave control enables the automatic change of the frequency adjustment operand. Considering that the resonant condition is necessary for the low switching loss of the switches, this novel control method is indispensable for the high-efficiency and safe operation of the system. Given the high-power level and high-voltage level, to avoid the inrush current at the start of the system, the DCX is responsible for pre-charging the output capacitor of the LVDC buses before charging. These control methods will be detailed in Section 3. Section 4 will discuss the impact on the grid. Section 5 is the conclusion.

\section{PFC-Stage Control}

\subsection{Power Balancing}

Since the basic control method of the totem-pole PFC has been widely discussed $[13,14]$, this paper will particularly focus on the power balancing among modules. To simplify the analysis, just consider two series PFC stages as shown in Figure 2.

To rectify the AC power from the power grid, the bridge leg of the PFC \#n $\{\mathrm{Sn} 3, \mathrm{Sn} 4\}$ is operated with main power frequency, i.e., $50 / 60 \mathrm{~Hz}$, which could be seen as the rectifier bridge leg. Another bridge leg of the PFC \#n $\{\mathrm{Sn} 1, \mathrm{Sn} 2\}$ is pulse width modulation (PWM) controlled to achieve the power factor correction and low THD. In the steady state of this system, because the voltage and current are in phase, the DCX could be considered as the resistive load. Because the switching frequency fs is much higher than the line frequency $f g$, $\operatorname{vin}(t)$ can be assumed as constant within one switching period. Considering the continuous conduction mode (CCM) for both PFCs, steady-state equations can be derived as follows [15]:

$$
\begin{gathered}
V_{o 1}\left(1-d_{1}\right)+V_{o 2}\left(1-d_{2}\right)=\left|V_{\text {in }}\right| \\
V_{o 1}=\left|i_{i n}\right| \cdot\left(1-d_{1}\right) \cdot R_{1} \\
V_{o 2}=\left|i_{i n}\right| \cdot\left(1-d_{2}\right) \cdot R_{2}
\end{gathered}
$$

where $d_{1}$ and $d_{2}$ represent the duty cycle of the high-frequency gate signals of PFC\#1 and PFC\#2.

From Equations (2) and (3), it can be seen that to achieve the output voltage balancing control under the unequal load condition, the duty cycles of two PFCs need to be modulated to accommodate 
the load difference $[15,16]$. Figure 3 shows the control block of the PFC weighted output voltage balancing control, composed of three loops, i.e., inner current control loop, outer voltage control loop, and the supplementary voltage balancing loop. The slower outer voltage control loop is to make the PFC stage output voltage follow the reference voltage and supply the reference current to the inner current control loop. The reference current is generated by the averaged voltage loop output $V_{\text {voa }}$ and the grid side voltage $V_{i n}$, where $V_{\text {voa }}$ supplies the magnitude and vin with its RMS value $V_{\text {in }}$ provides the phase of the reference current.

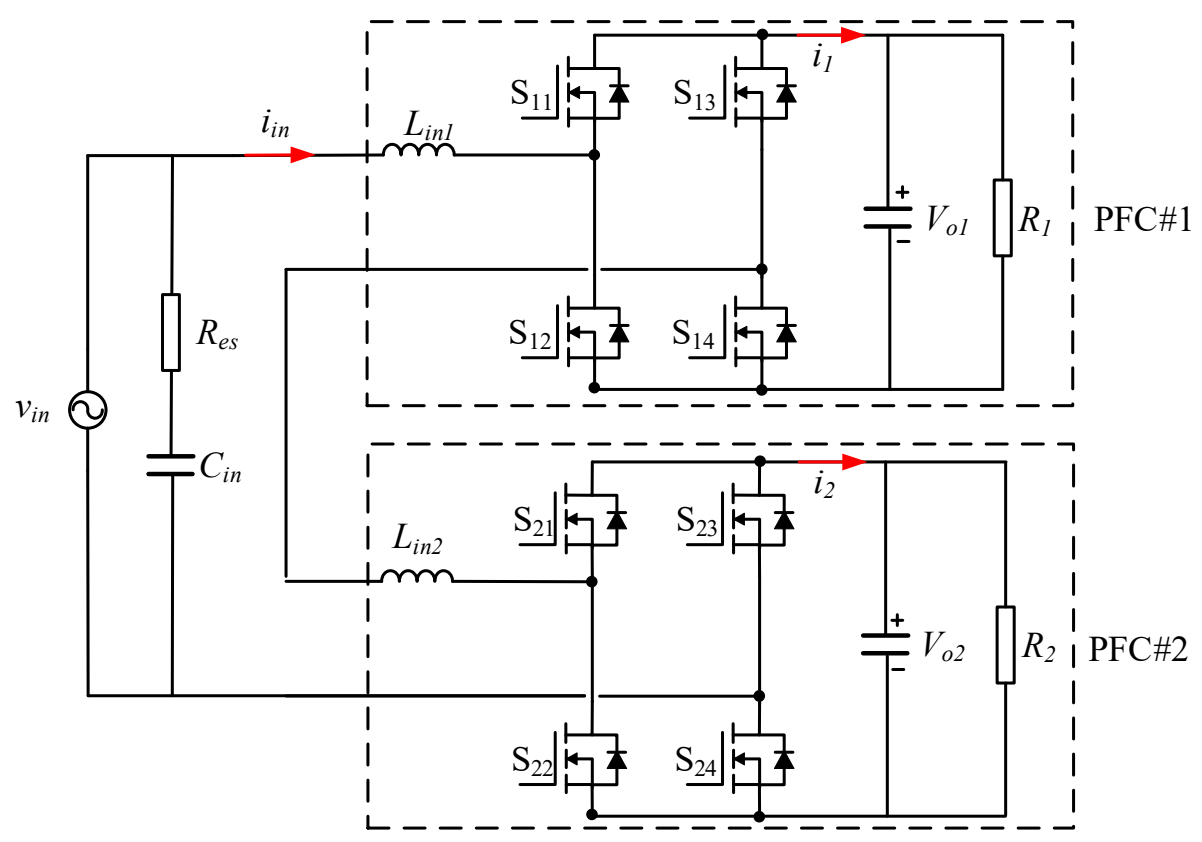

Figure 2. Schematics of two power factor correction (PFC) modules in series.

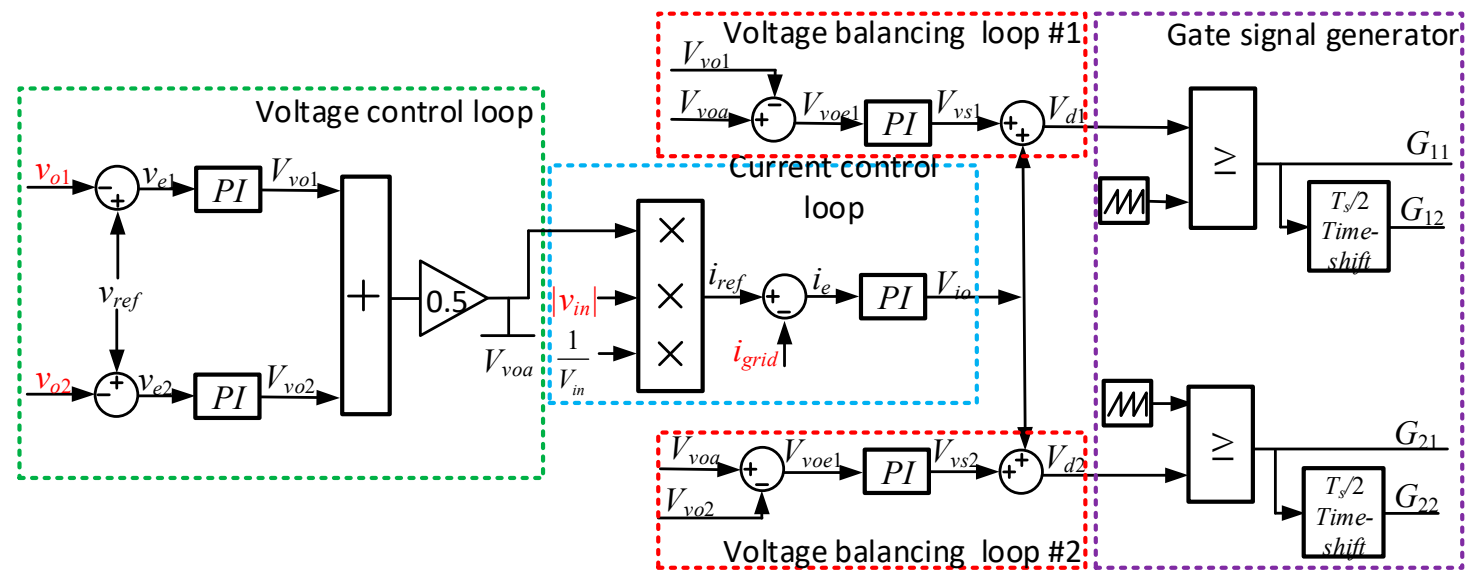

Figure 3. Control scheme for series-connected PFC modules.

The impact of the load difference is thereby eliminated through the voltage balancing control loop, as simulated in Figure $4 \mathrm{a}, \mathrm{b}$, where the load of each PFC is not identical, $R_{2}=1.1 R_{1}$. Without balancing control, some diversity of the switch can cause the DC-bus variation. Based on Equations (2) and (3), the same duty cycle will be supplied to two PFCs. Because of the series input structure, the input current will be the same for two PFCs. Therefore, the different load resistance will cause the unbalanced output. The simulation results of the steady-state output voltage waveform without the balancing control is shown in Figure 4a. When the voltage balancing loop is integrated into the control loop, two 
PFCs can be controlled individually. Voltage balancing loop could compensate for the deviation of the duty cycle caused by the different loads. After the compensation, the different duty cycle generated based on the output voltages of two PFCs will be supplied to the corresponding PFCs, such that the balanced output could be achieved. Figure $4 \mathrm{~b}$ shows the voltage balancing control performance based on the simulation model. We then further experimentally validated the voltage balancing control for PFC stages, where we consider the load resistances of two PFCs to be $2 R_{1}=R_{2}=25 \Omega$. The experimental setup and the Field Programmable Gata Array (FPGA) control block diagram is shown in Figure 5, and the experimental results are shown in Figure 6. Figure 6a shows the steady-state input and output waveform without the balancing control. It can be seen that the output DC voltage of PFC\#1 is almost twice of the output DC voltage of PFC\#2. Considering that the load $R_{2}$ is twice of the load $R_{1}$, the experimental results are consistent with the theoretical analysis. As shown in Figure 6b,c, after integrating the voltage balancing control, the DC bus voltages are kept the same once the system reaches steady state. Therefore, the voltage balancing control method is validated by the simulation and experiments.

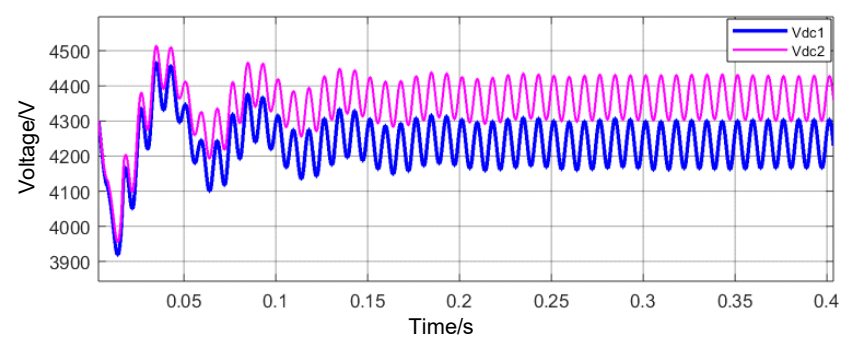

(a)

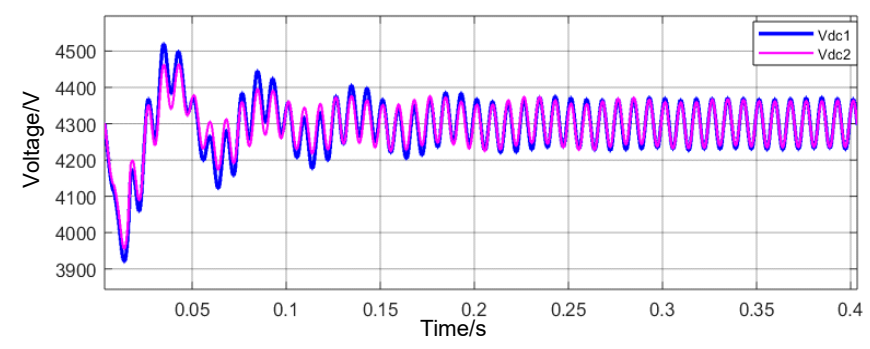

(b)

Figure 4. Simulation results of the DC output voltage for series-connected PFC modules: (a) without the balancing control and (b) with the balancing control.

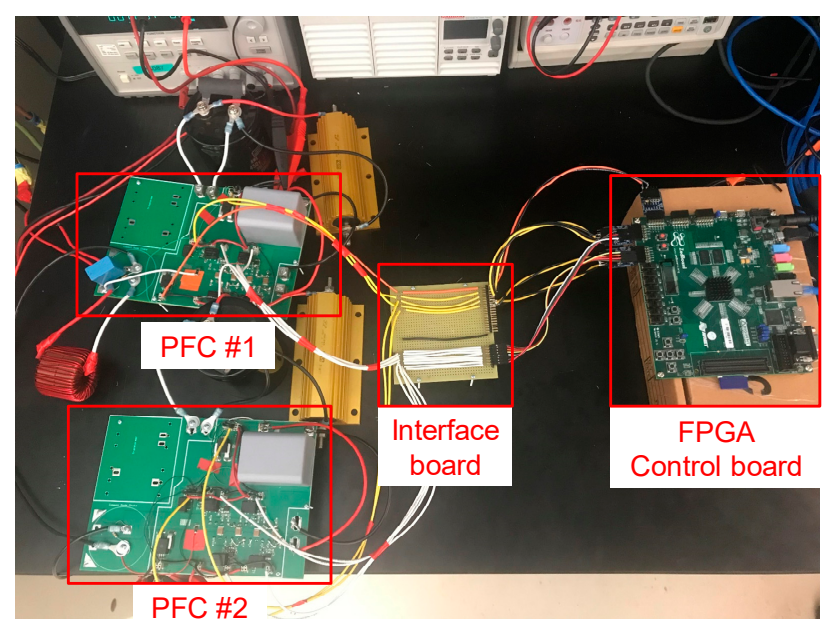

(a)

Figure 5. Cont. 


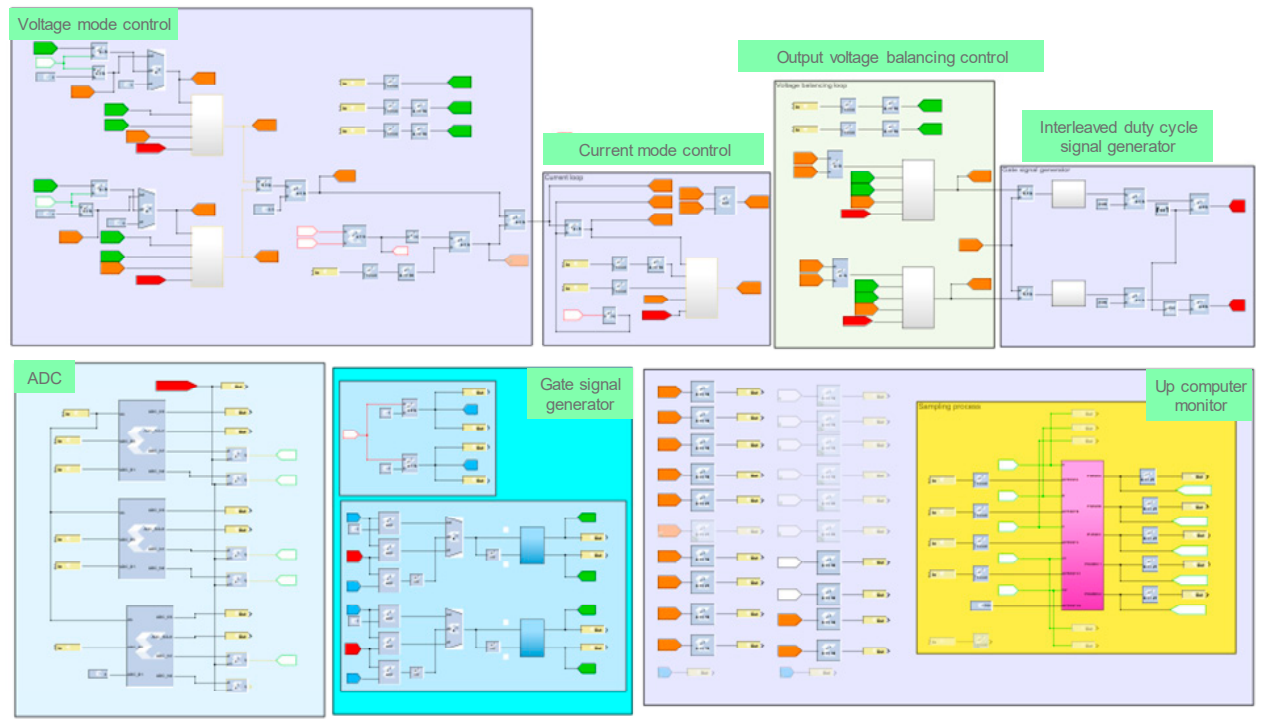

(b)

Figure 5. (a) Experimental setup of two input series-connected PFC; (b) FPGA control block diagram.

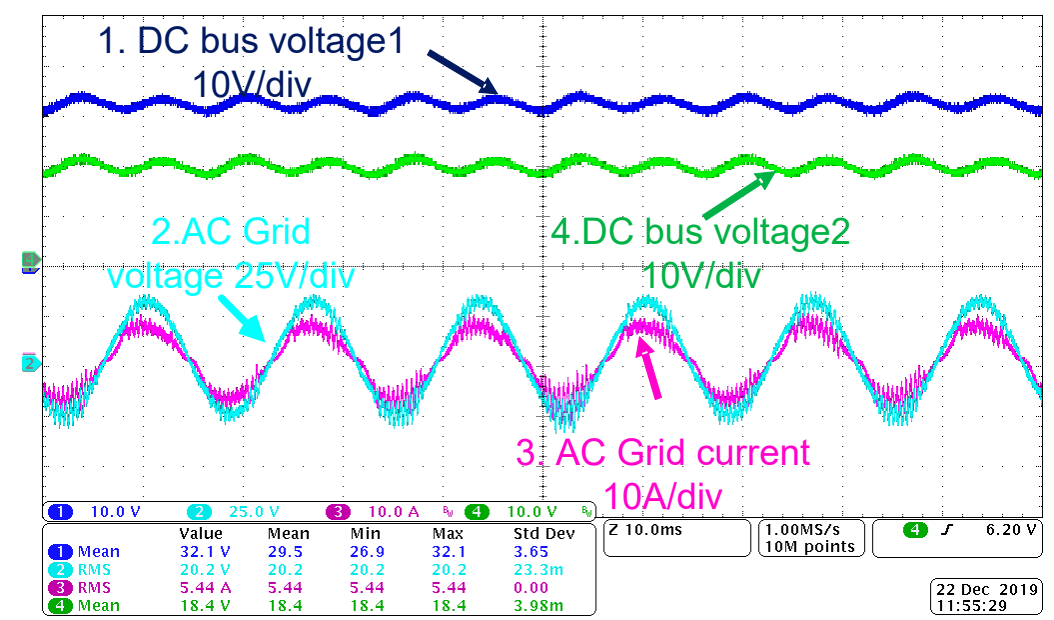

(a)

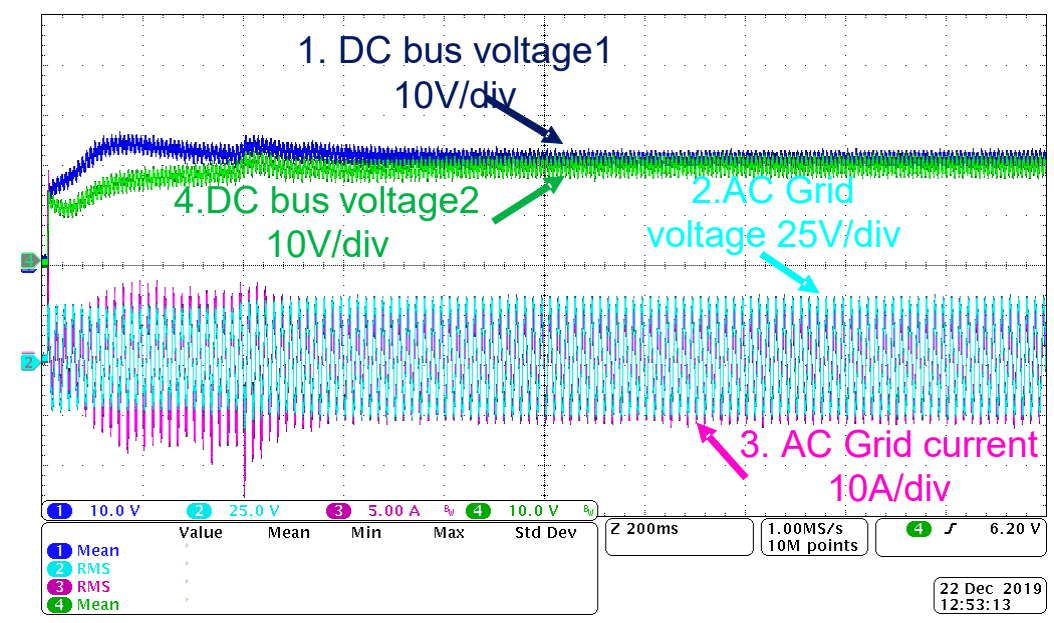

(b)

Figure 6. Cont. 


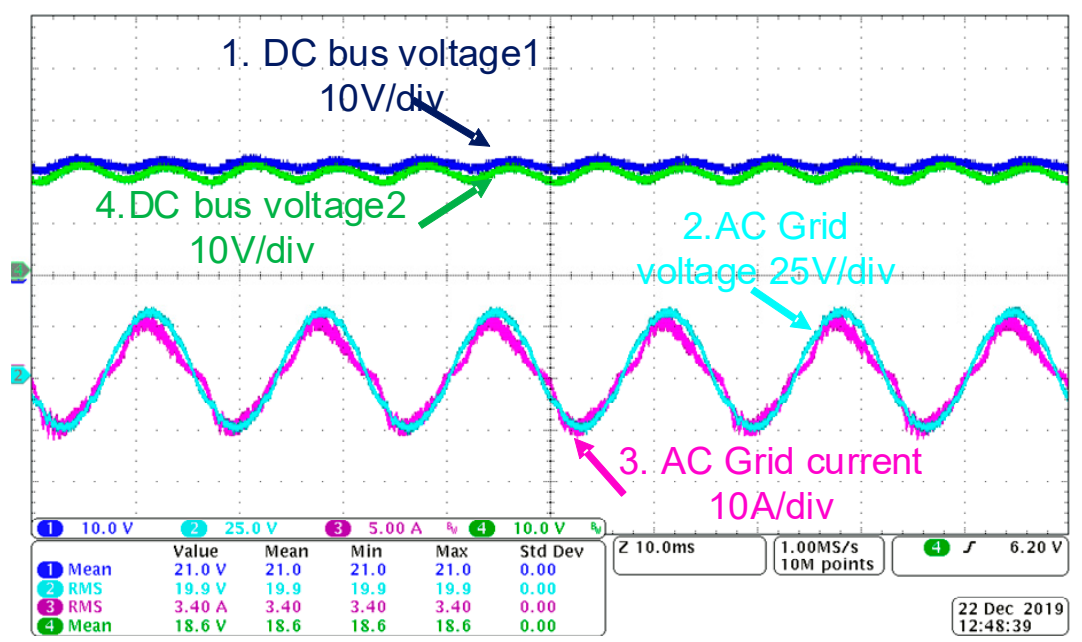

(c)

Figure 6. Experimental results for series-connected PFC modules (a) without the balancing control; (b) with the balancing control and (c) Zoom-in view with the balancing control.

\subsection{Interleaving Control}

Once the three PFC modules balance the power in the modules, we can further employ interleaving control for each PFC, i.e., shifting the gate signals by $120^{\circ}$ (1/3Ts). This helps further reduce the grid-side current. As shown in Figure 7a, without the interleaving, the grid side current (I_inductor) sees over 20 A current ripple. With the interleaving control, as shown in Figure $7 \mathrm{~b}$, the grid current ripple drops to $\sim 5 \mathrm{~A}$.
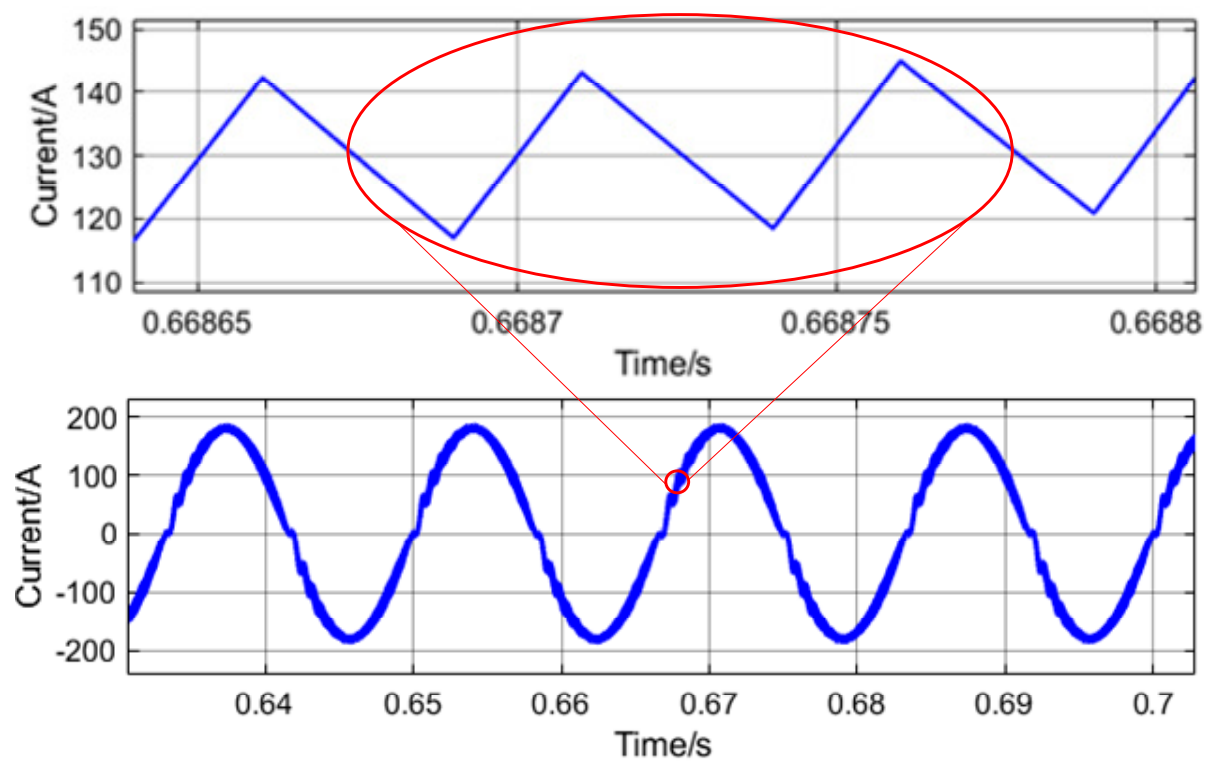

(a)

Figure 7. Cont. 

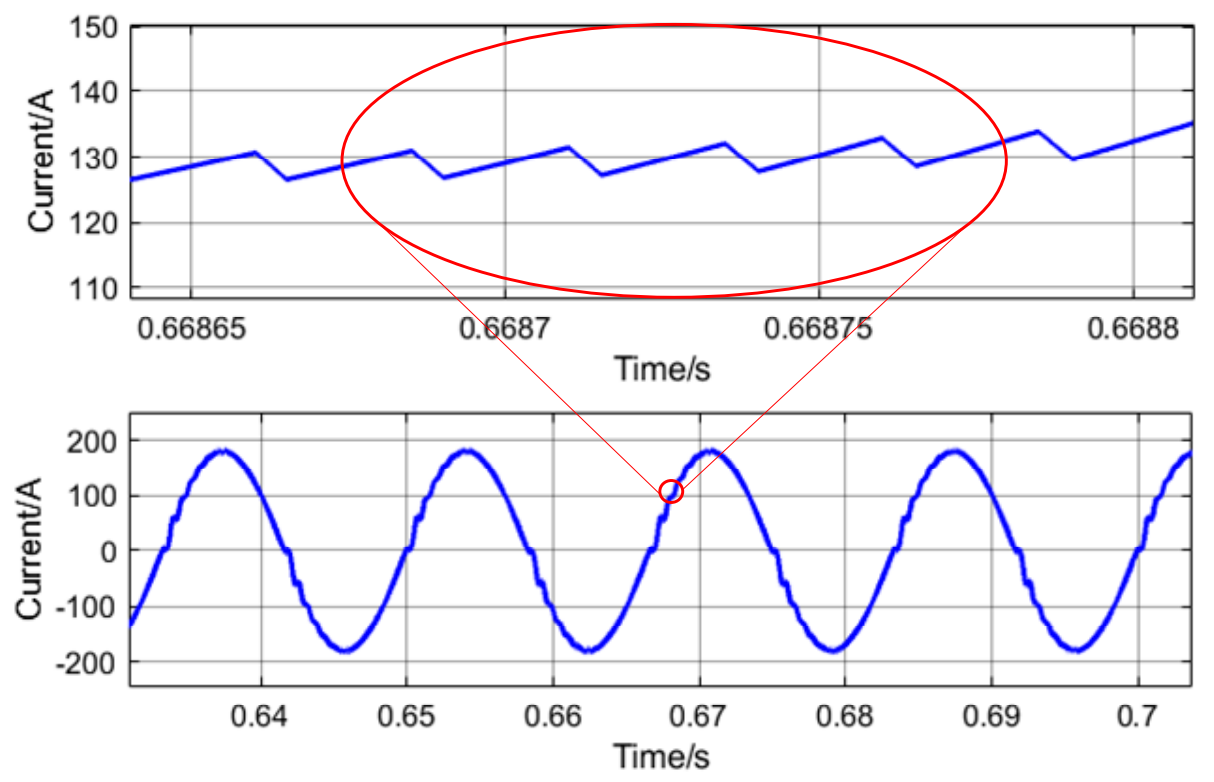

(b)

Figure 7. Simulated grid current (a) with same gate signal and (b) with interleaving gate signal.

\section{DCX Stage Control}

\subsection{Power Balancing Control}

The DCX converter topology, as seen in Figure 1a, consists of a MOSFET half-bridge converter on the primary side, a three-winding MV transformer, a resonant capacitor and a MOSFET full-bridge converter on each secondary side. The primary-side and secondary-side MOSFETs share the same complementary PWM gate signals with 50\% duty cycle. The relationship of the resonant frequency $f_{r}$ and the resonant parameters can be expressed by Equation (4), where $L_{r}$ is the leakage inductance of the transformer and $C_{r}$ represents the capacitance of the resonant capacitor.

$$
2 \pi f_{r}=\frac{1}{\sqrt{L_{r} C_{r}}}
$$

As previously mentioned, the PFC stage could achieve balanced output voltage, which means that each of the DCX converters will have the same input voltage. However, a slight difference between transformers leakage inductance or the resonant capacitance will lead the converter to deviate away from the resonance point and further creates an unbalanced output current. The main challenge of this unbalanced problem is that when the switching frequency is higher or lower than the actual resonant frequency of the DCX, they both can cause the output current to decrease and unbalance the outputs. Thus, we need to detect the impedance of the resonant tank to determine the changing direction of the switching frequency. To solve this problem intelligently and easily, output current balancing control based on the resonant frequency control is proposed in this paper and shown in Figure 8.

It is noticeable that when the switching frequency of one DCX converter in this paralleled structure is closer to its resonant frequency, its output current will be larger. Thus, in this control method, the DCX converter which has the highest output current will be set as the master converter, and other DCX converters will automatically become the slaves. The frequency of the master will be constant, and the frequency of the slave will be adjusted to match the resonant frequency of the DCX converter. The resonant frequency tracking control is mainly controlling the changing direction of switching frequency based on the changing of the output current. The time step ts and frequency step $\Delta \mathrm{f}$ are constant and can be adjusted according to the system parameters and requirements of the control accuracy. Then, if the output current of DCX \#n increased after the last change of the frequency (when 
time $\left.t=(k-1) t_{\mathrm{s}}\right)$, the changing direction of the frequency will stay the same as the last time (when time $t=k t_{\mathrm{s}}$ ). Conversely, the frequency will change in the opposite direction. The control goal is to track the resonant frequency of each DCX automatically and achieve the balanced output currents.

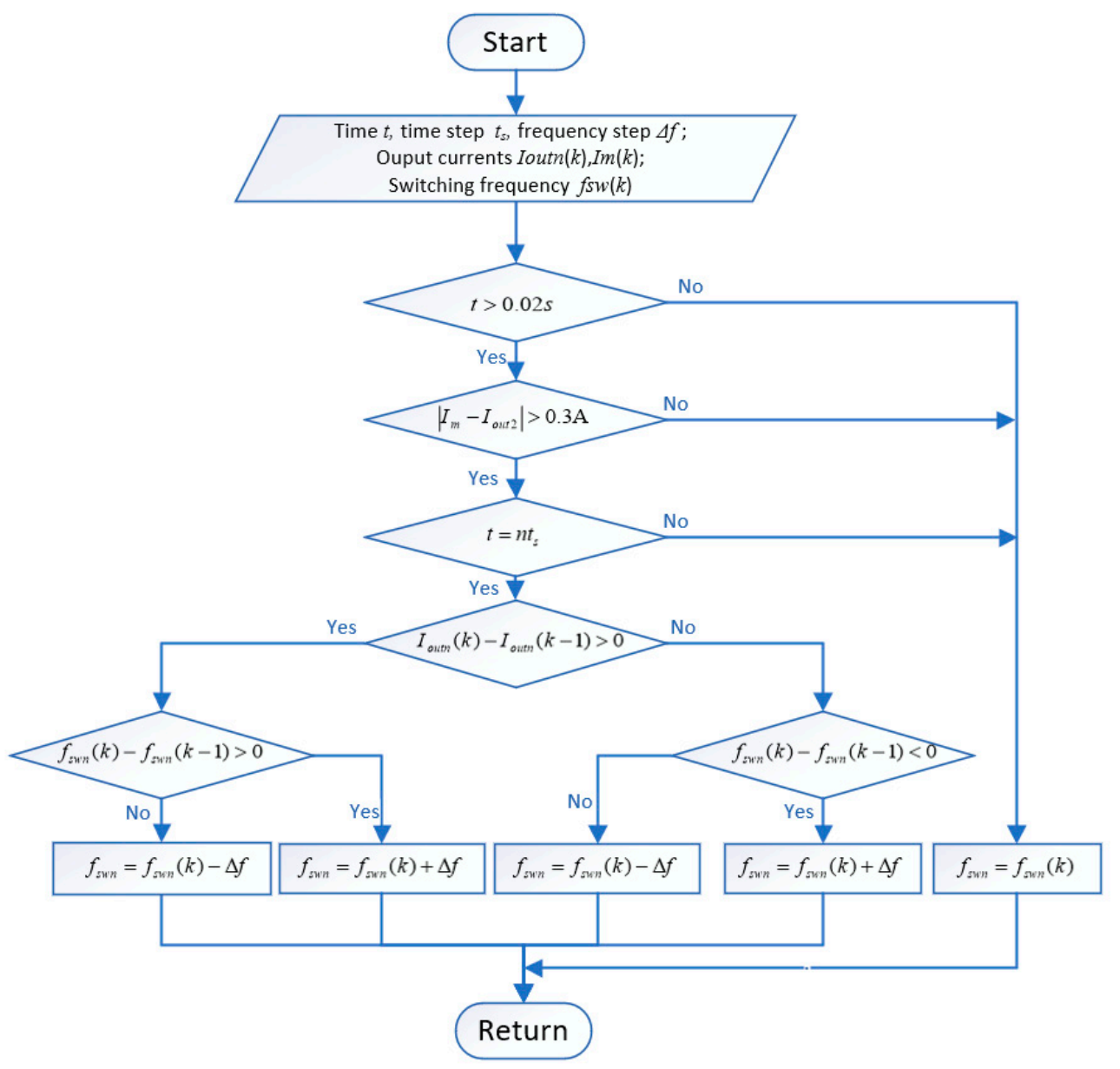

Figure 8. Algorithm depicting output current balancing control of the paralleled DC transformer circuits (DCXs).

Compared with the control method based on phase relationship detection [17] and time measurement of zero diode current [18], among others, the proposed method has three main advantages: 1) changing fs bi-directionally and automatically tracking the resonant condition; 2 ) setting the master automatically to make all the DCX converters work under the resonant conditions when the system is at the steady state; and 3) having no extra detection and measurement circuit.

Based on three paralleled DCXs, the simulation is conducted to validate the output current balancing control. Three DCXs have different resonant inductors but have the same initial working frequency $f_{\text {initial }}$ :

$$
f_{\text {initial }}=\frac{1}{2 \pi \sqrt{L_{r d} C_{r d}}}=20 \mathrm{kHz}
$$

where $L_{r d}$ and $C_{r d}$ represents the designed resonant inductance and capacitance.

Figure $9 \mathrm{a}, \mathrm{b}$ shows the output current balancing process of three parallel-connected outputs under two sets of different initial parameters of inductors, 1) $L_{r 1}=L_{r d}, L_{r 2}=0.9 L_{r d}, L_{r 3}=0.95 L_{r d}$ and 2) $L_{r 1}=1.05 L_{r d}, L_{r 2}=0.9 L_{r d}, L_{r 3}=0.95 L_{r d}$. For the first set, based on the control algorithm, there are mainly three stages for the balancing process. First, when $t<0.02 \mathrm{~s}$, the system works without the balancing control, and the output currents are unbalanced, which is caused by the different resonant condition. From Figure 9a, when $t<0.02 \mathrm{~s}$, it can be seen that the DCX\#1 with the best resonant 
condition has the largest output current, which is consistent with the theoretical analysis that a better resonant condition will lead to larger output current. Then, when $t>0.02 \mathrm{~s}$ and before the system reaches the balanced condition (where the deviation of currents are less than $0.3 \mathrm{~A}$ ), the first DCX is the master controller as it has the largest current and the other two DCXs become the slave automatically. The frequency of the master converter will keep consistent, and two slaves will adjust the frequency to reach the resonant frequency based on the algorithm. Finally, when the output currents reach balance, the algorithm will automatically stop changing the frequency and keep the system working under this steady-state condition. Similar to the first set, the modulation process of the second set also has three modulation stages, which are shown in Figure $9 \mathrm{~b}$. The difference is that, for the second set, DCX\#1 and DCX\#3 have similar frequency deviation, so at first, the output current of these two DCXs are close to each other.

Figure 10 shows the voltage and current waveforms of the transformer primary sides of DCX\#2 before and after the DCX reaches the resonant condition. After the DCX reaches the resonant condition, the transformer current waveform changes to a sinusoidal waveform, and the current and voltage are exactly in phase, which indicates zero-current switching-on and -off loss. Figure 11 shows the frequency modulation process of DCX\#2 and DCX\#3 when the system works under the first set of the parameters of inductance shown in Figure 9a. From Figure 11, we can find that first, the DCX\#2 and DCX\#3 could modulate the frequency to the real resonant frequency, which is determined by the inductor and capacitor, based on the deviation of the resonant frequency; and second, when the system reaches the resonant condition, the frequency modulation will stop and the controller will keep the frequency constant, such that three DCXs will work on the steady state with balanced outputs.

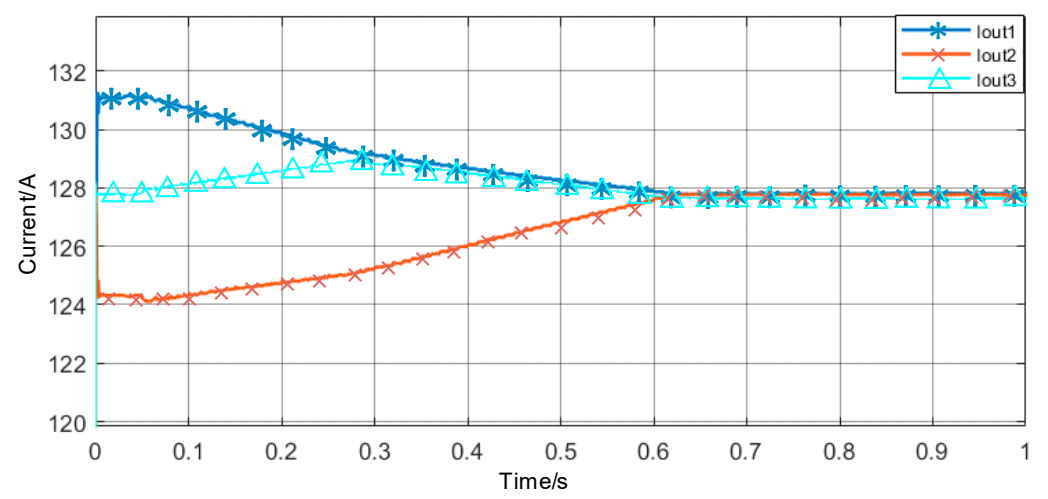

(a)

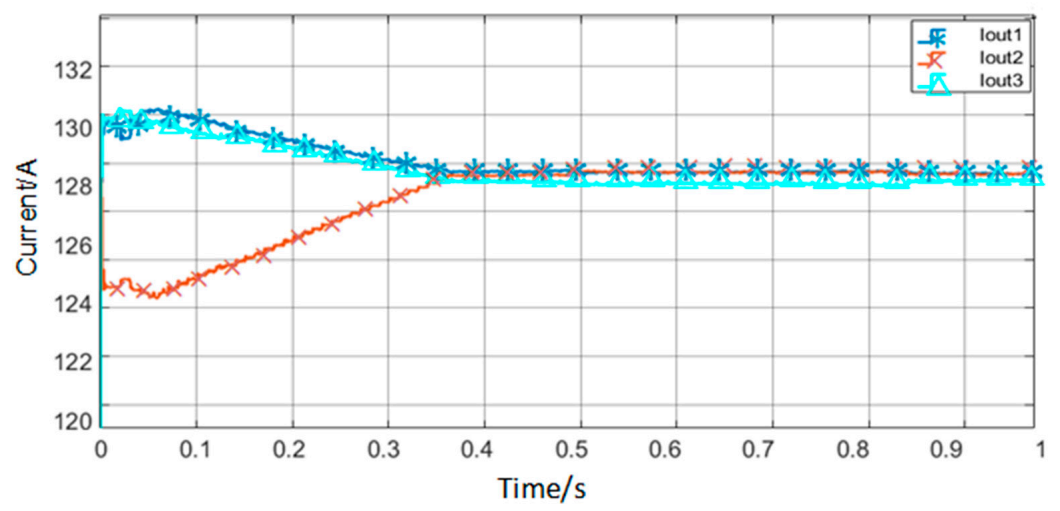

(b)

Figure 9. Output current balancing control performance with the resonant inductance of (a) $L_{r 1}=L_{r d}$, $L_{r 2}=0.9 L_{r d}, L_{r 3}=0.95 L_{r d}$ and (b) $L_{r 1}=1.05 L_{r d}, L_{r 2}=0.9 L_{r d}, L_{r 3}=0.95 L_{r d}$. 


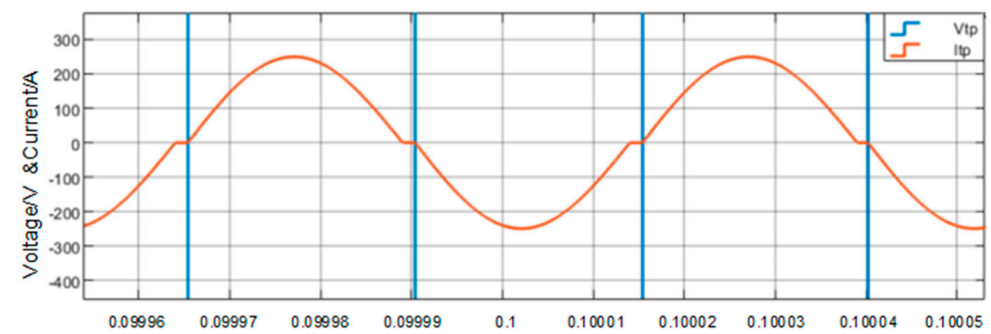

(a)

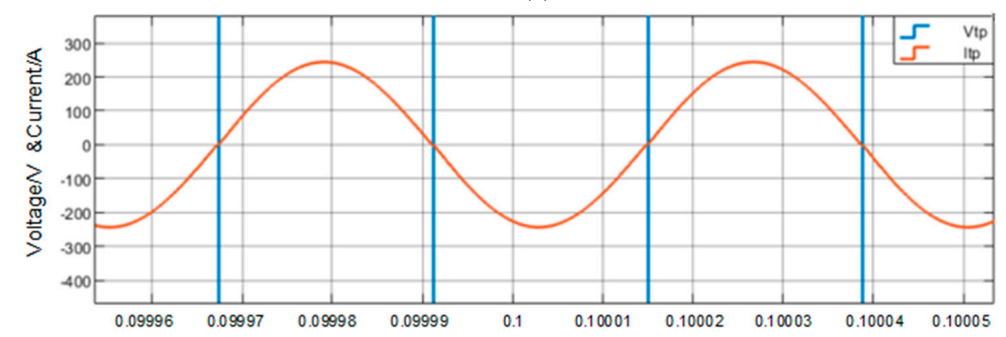

(b)

Figure 10. Voltage and current waveforms of the primary side of the DCX transformer (a) before the DCX reaches the resonant condition and (b) after the DCX reaches the resonant condition.

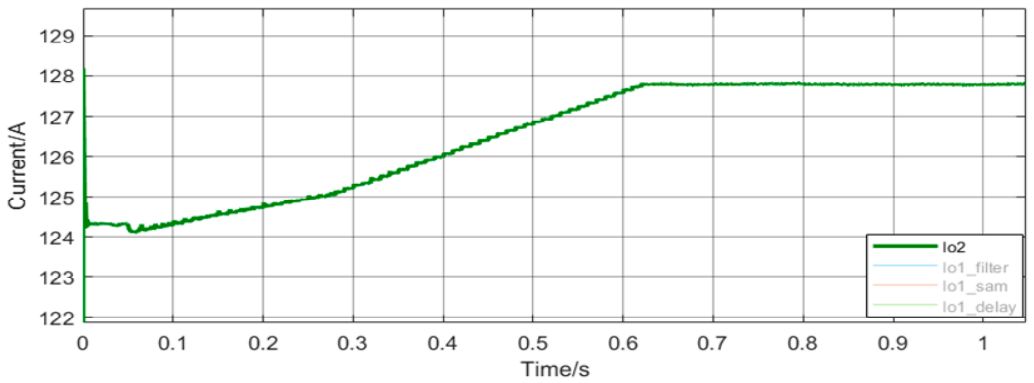

(a)

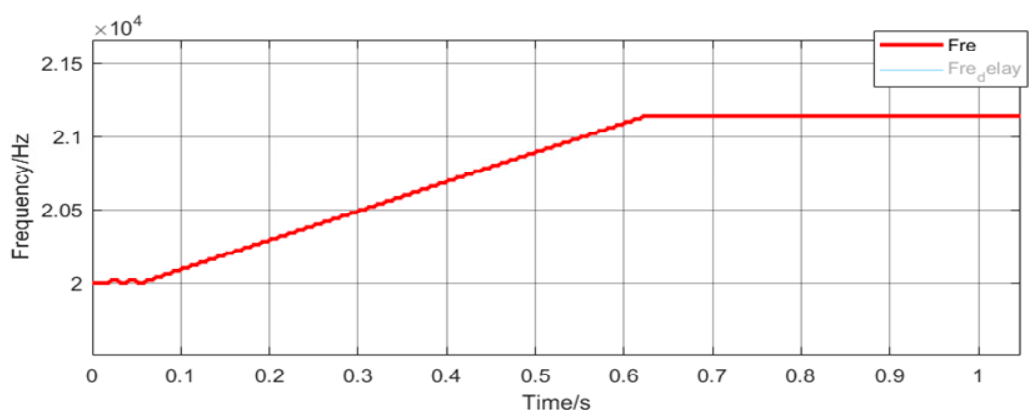

(b)

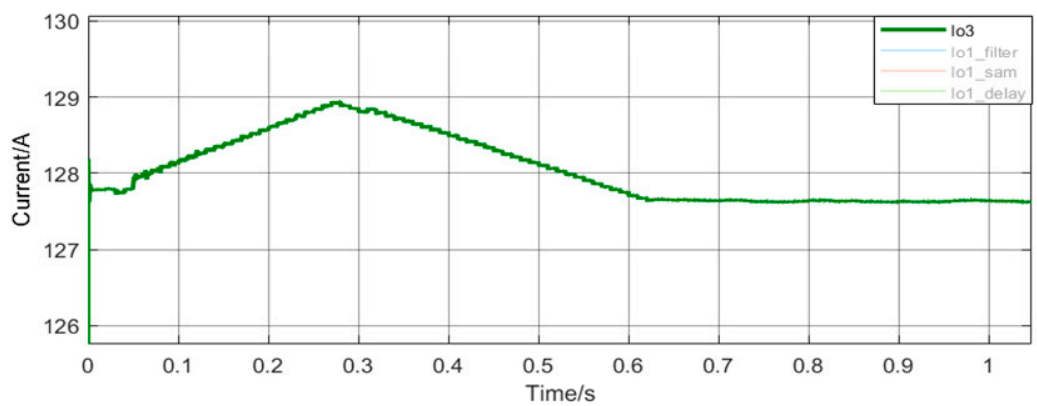

(c)

Figure 11. Cont. 


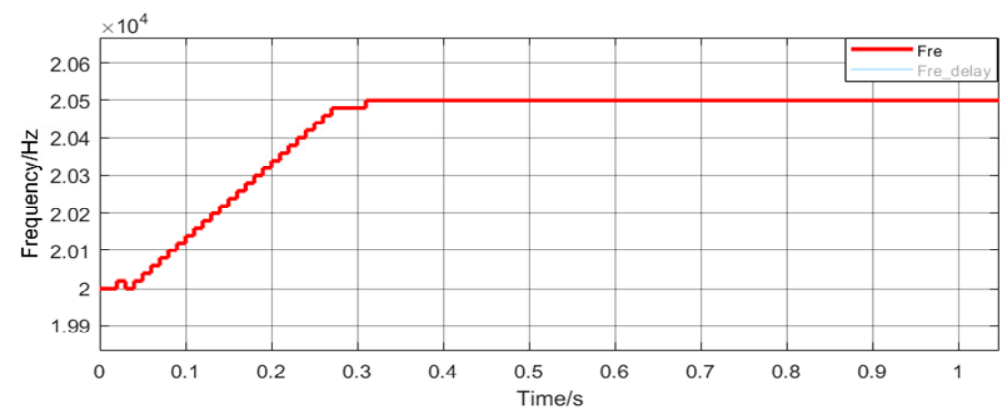

(d)

Figure 11. Output current and switching frequency regulation of the DCX\#2 and DCX\#3. (a) Output current changing with the switching frequency of DCX\#2; (b) Switching frequency regulation of DCX\#2; (c) Output current changing with the switching frequency of DCX\#3 and (d) Switching frequency regulation of DCX\#3.

\subsection{Pre-Charging Process}

Considering high power and voltage level, we need to pre-charge the output capacitor of the LVDC bus before starting to charge the vehicle. Given the nature of its voltage source, directly providing $50 \%$ duty cycle for all switches will induce the large inrush current [19]. Instead, we propose to use a smaller duty cycle for the primary-side switch of the DCX in the starting process and prolong the charging time. The simulation results of pre-charging control are shown in Figure 12. Figure 12a shows the pre-charging process; meanwhile, Figure $12 \mathrm{~b}$ shows the duty cycle of the gate signal changing process. When the system works at steady state, for DCX, the gate signals for the primary and secondary side switches are exactly in phase and with duty cycle of $50 \%$. Differently from the steady state, when the system works on pre-charging stage, the duty cycle of the primary side will increase gradually from $0 \%$ to $50 \%$. In this way, we can make sure that the charging power is small at first, which could decrease the $\mathrm{dv} / \mathrm{dt}$ and charging current of the DC bus capacitor. Figure 12c shows the waveform of the current and voltage during the pre-charging process. From Figure 12c, we can find that the duty cycle smaller than 50\% could decrease the current flowing to the capacitor, which is achieved by smaller conduction time. Figure $12 \mathrm{~d}$ shows the relationship of the pre-charging time and peak value of the current flowing through the primary side switches. The peak current can be seen decreasing as the pre-charging time is increased, which could help to choose the appropriate pre-charging time based on the current rating of devices.
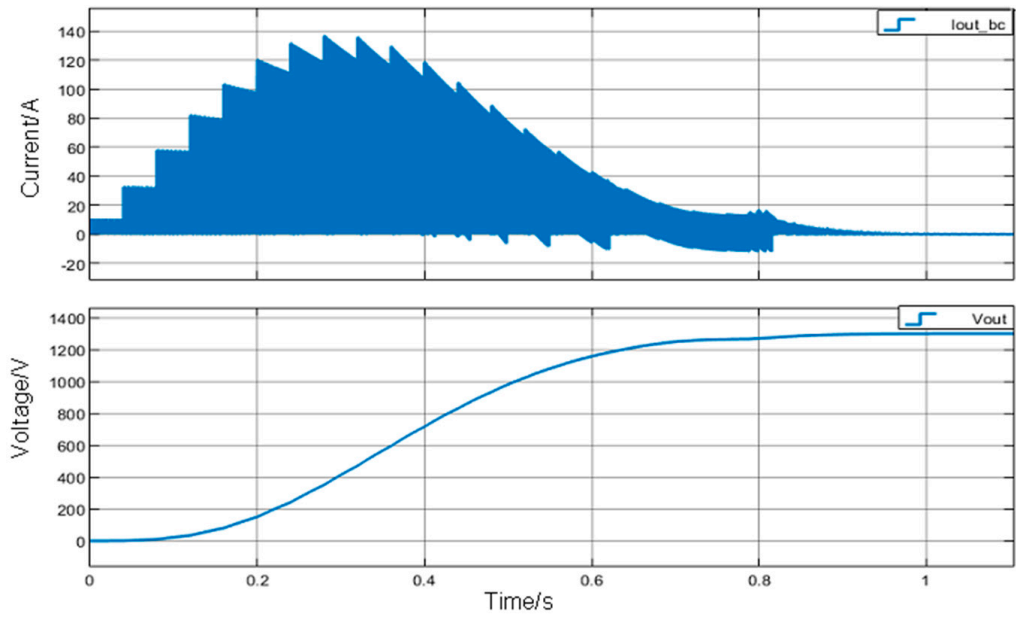

(a)

Figure 12. Cont. 

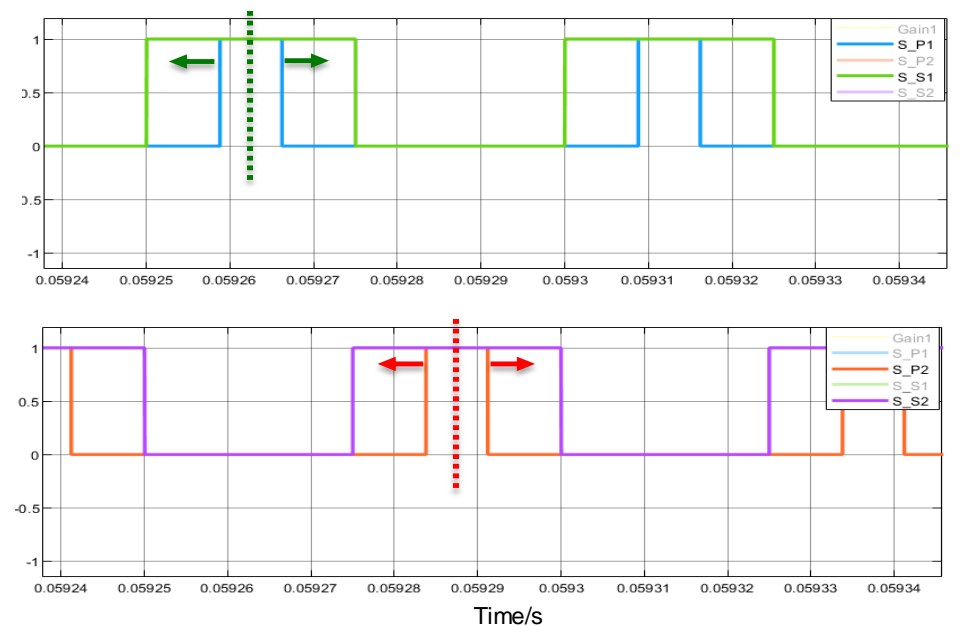

(b)
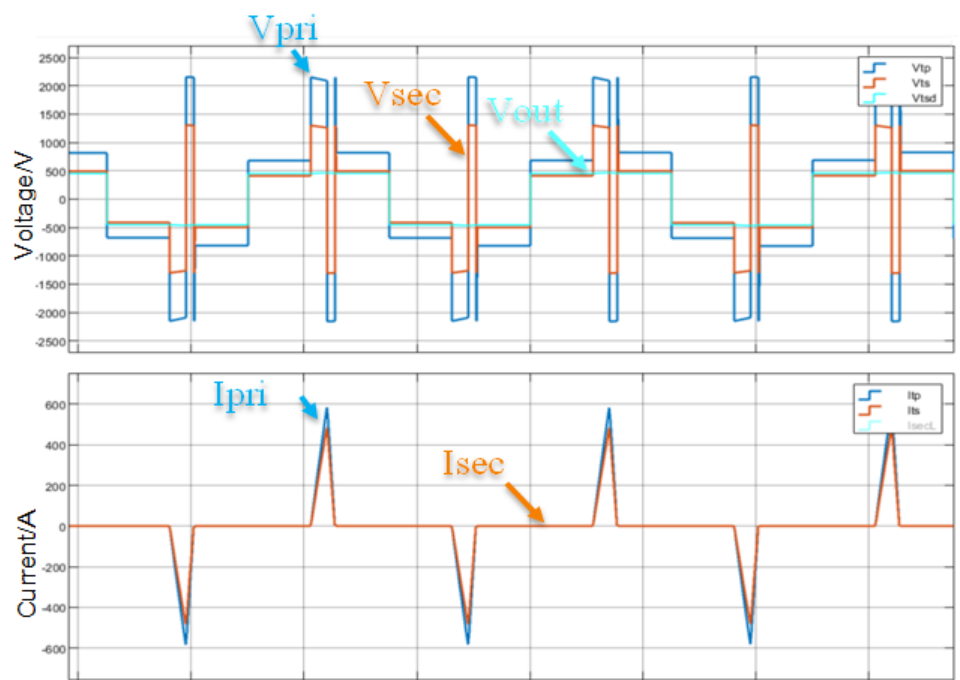

(c)

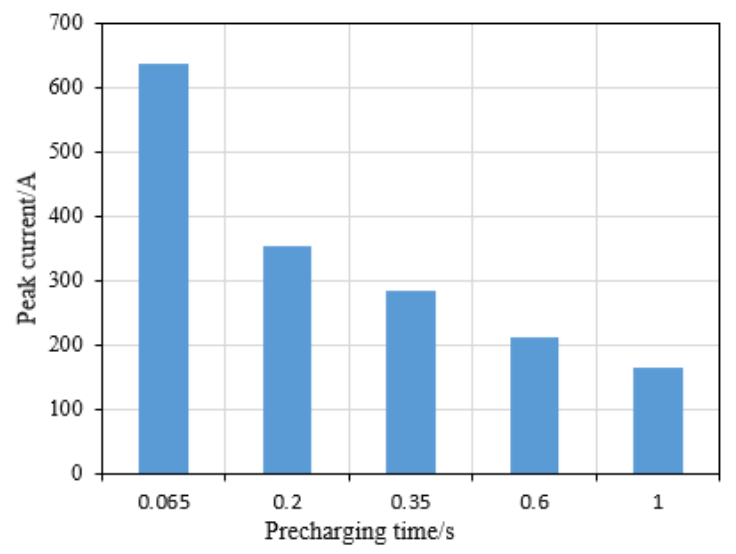

(d)

Figure 12. Pre-charging mode of the DCX stage. (a) Pre-charging process when the pre-charging time $=1 \mathrm{~s}$; (b) Gate signals modulation of the switches; (c) Zoom-in waveform of primary and secondary voltage and current; and (d) Relationship of the peak current and pre-charging time. 


\section{Interaction with the Grid}

How to fit such a charger to the grid is another concern of this study. In this study, we are using a quasi-steady-state approach with a one-hour resolution to study the effect of installing XFCs on the feeders. For this purpose, the highest load day in 2019 has been picked and the one-hour snapshots of the grid have been selected as the base cases. The snapshots are basically real-time models of the network generated from the real energy management system (EMS) data by state estimators. Topology changes, load variations, generation units' dispatch, and all other grid specifications that are subject to change are included in these models. These snapshots are being generated every ten minutes, but since the demand model for the XFC demand has a one-hour resolution, the snapshots are chosen accordingly. The models are real models of "Utility D".

The XFC demand model that has been chosen for this study is the model that has been suggested in [20]. Authors suggested this demand model based on field data surveys and used statistical methods to generate a MW/time model for the demand for a week, which is shown in Figure 13. What we are using is an hourly demand model for a day which has the highest value during the week.

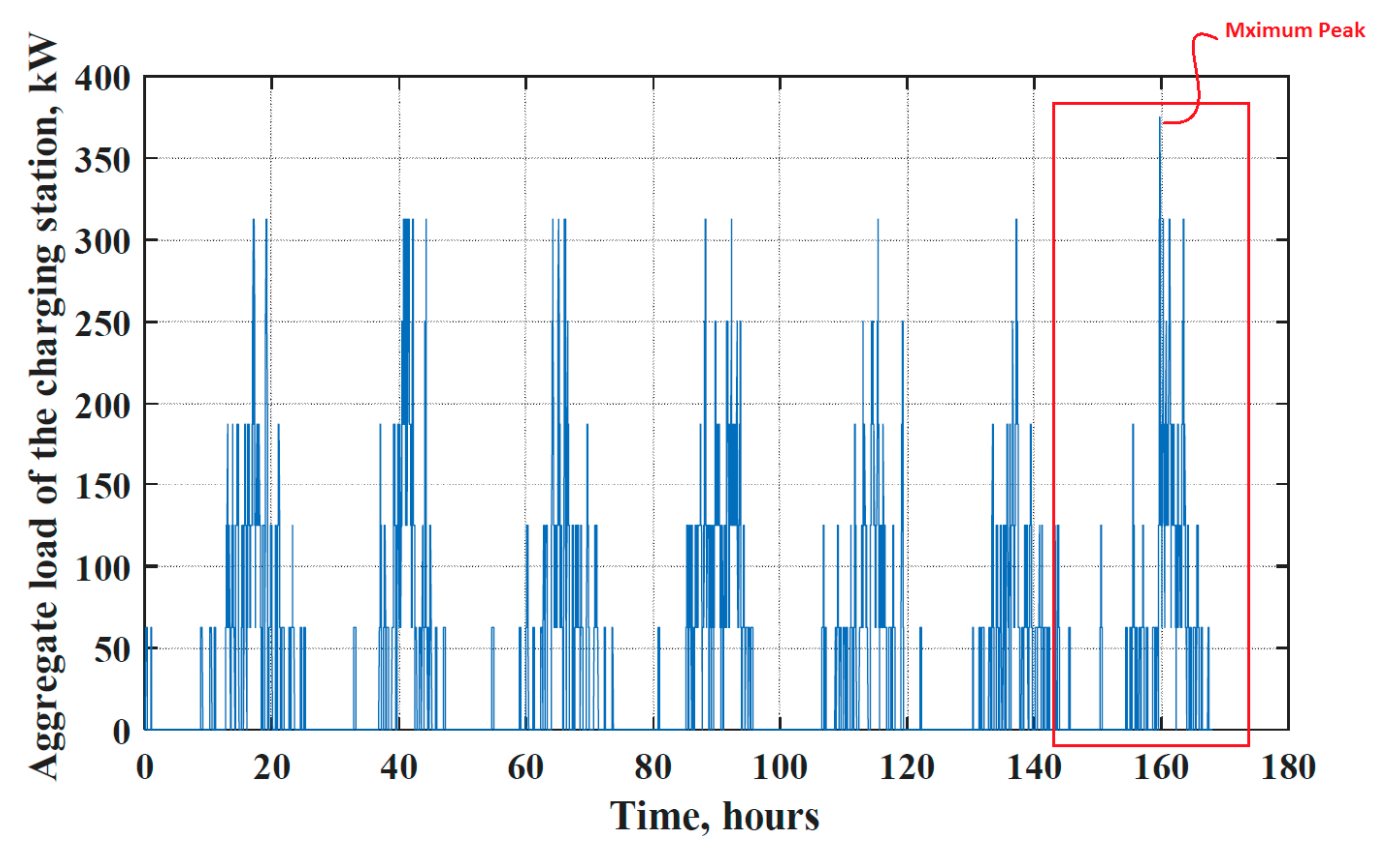

Figure 13. Demand MW/Time model of an XFC station during a week for a $\sim 500 \mathrm{~kW}$ station.

In our study, to have a more realistic sense of the effect of chargers on the higher-level grid, we have considered $20 \%$ of maximum loadability of the Transmission/Distribution transformer as the aggregated nominal charging power of the stations which are installed at the feeder. The MW demand associated with the time of the day is being added to a certain predetermined substation in the corresponding snapshot. For example, MW demand for 23:00 is added to the substation in the 23:00 snapshot. For each location, it is done for $24 \mathrm{~h}$ of a day. Then, the voltage variation, voltage violation, and transformer rating violation are monitored during the day. The results are further investigated for the aforementioned penetration of the EV chargers in the selected locations.

The first step for implementing the study was to choose the substations and geographic areas which make sense in the real world to install XFC stations. Through the field research from operational planning engineers in "Utility D", five different areas with 19 transformers in total have been selected as candidates for the study. These areas are mostly airport, commercial, residential, or touristic areas in the state. All the locations in one area are studied together so that we can have a good understanding of how moving the XFC station might affect the grid locally. In all cases, the power factor has been considered. Therefore, the station is not absorbing any reactive power from the network. 
To explain the research findings compactly, only the simulation results of four feeders in Area 2 are shown in Figure 14. Other areas have similar results with Area 2. Area 2 is mostly an important business area with four feeders as the options for connecting the XFC stations. From Figure 14a,b,d, we can find that $t x-05, t x-06$ and $t x-08$ are able to supply the demand while the stations are working throughout the day. At feeder tx-07, there is a voltage violation at 3 p.m, which can be found in Figure 14c. Although, the voltage violation also exists in the base case, the $2 \%$ voltage drop due to charging load at the time intensifies the problem and might cause a relay action at the location. This case could cause trouble and needs further study. As can be seen from Figure 14, the planner might decide to move the station to another feeder or to take remedial action by installing capacitor banks in the same location.

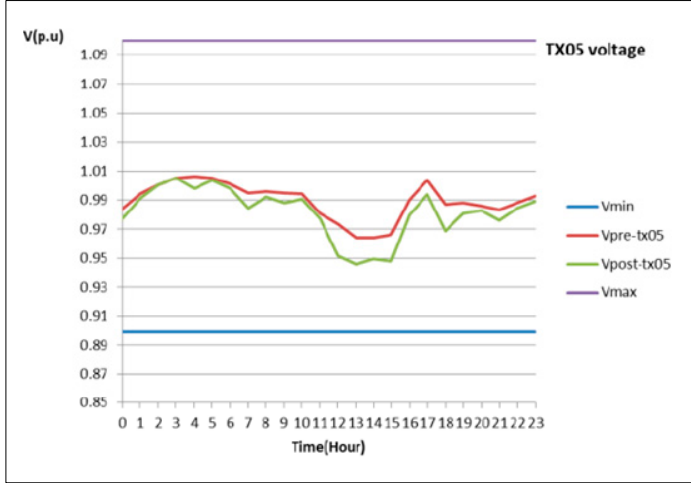

(a)

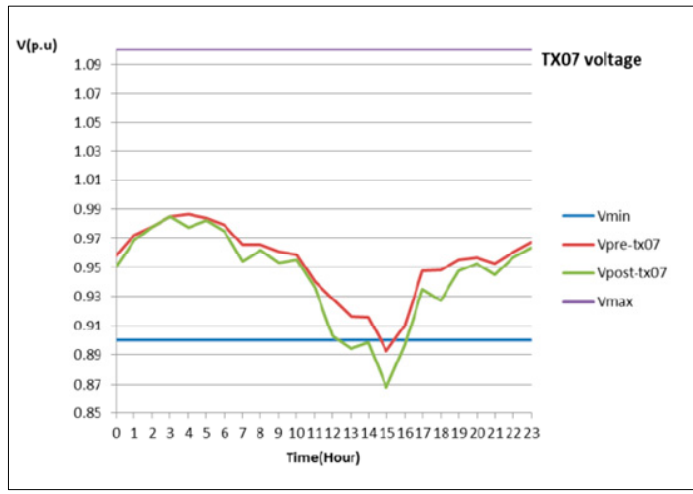

(c)

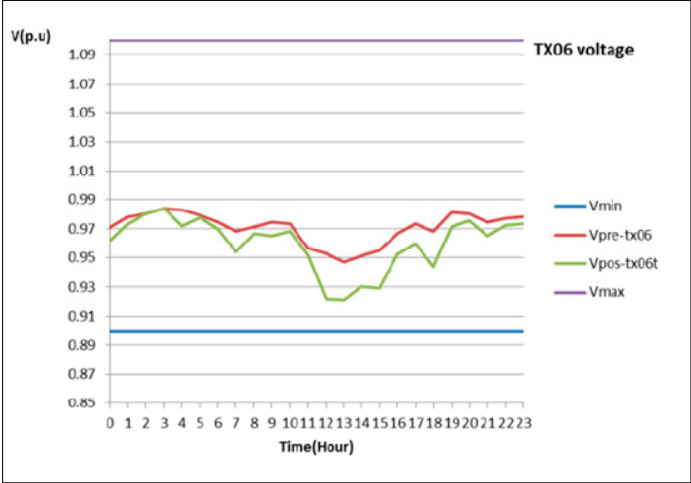

(b)

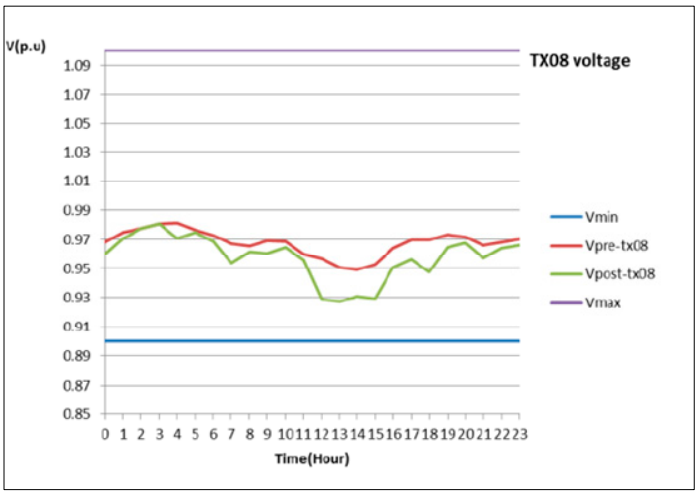

(d)

Figure 14. Voltage profile of feeder head before and after XFC installation on $20 \%$ penetration in area 2. (a)TX05; (b)TX06; (c)TX07 and (d)TX08.

As has been presented in the last section, we have observed voltage violations on the transformers after XFC integration to the network in four feeders. The voltage problem can be solved using conventional solutions like changing taps or switching in the capacitor banks, if any exist at the location. But in this section, we tend to evaluate the potential use of reactive power injection from the chargers to the grid. This could shed light on the possibility of using the converters as voltage improvement devices so that at least they do not worsen the voltage condition at the feeder at which they are connected. For the purpose of this study, we consider four different scenarios for all five feeders that have a voltage problem. The first scenario is the base case scenario before any station is attached to the grid. The second scenario is the same as we have demonstrated in the previous section. The third scenario is to deploy half the capacity of reactive power (VAR) injection of all stations. Typically, the converters are designed to be able to provide reactive power equal to 1.7 times of their nominal active power. Therefore, the half capacity of the VAR injection will be $0.85 \mathrm{MW}$. The fourth 
scenario is applying the full capacity of VAR injection, which is $1.7 \mathrm{MW}$. From Figure 14, we know that the voltage profile of the $\mathrm{tx}-07$ is not ideal even before the installation of the XFC station. To improve the voltage profile, four scenarios are applied to the tr-07, and the results are shown in Figure 15.

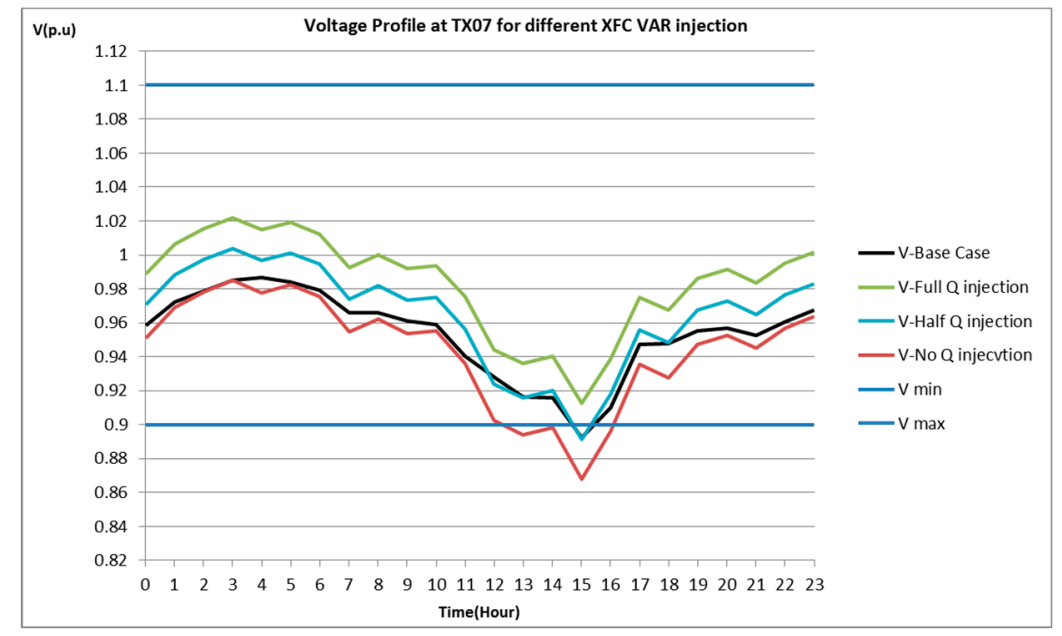

Figure 15. Voltage profile on tx-16 in different scenarios.

At tx-07, when we use half VAR capacity, the voltage profile improves significantly; meanwhile, the daily voltage dip is restored to base case level. At full-capacity VAR injection, there will not be any voltage violation as it can be observed. Therefore, to successfully deploy such XFC, the PFC stage should not always work at unity power factor. When the grid voltage dips, it needs to generate capacitive reactive power to back up the grid.

\section{Conclusions and Future Work}

A single-phase $1 \mathrm{MW}$ EV XFC station is presented in this paper. Essentially, this is an input-series, output-parallel design that includes a PFC stage and DCX per module. This paper addressed the output voltage balancing control of the series-input PFC considering the unbalanced load condition. The integrated voltage balancing control loop could compensate for the deviation of the duty cycle and achieve the independent control of two PFCs, which could satisfy the output voltage balancing. Considering the paralleled output structure of three DCXs in our model, the output current balancing control is proposed to compensate for the resonant frequency deviation in this paper. Based on the master-slave resonant frequency modulation control, the working frequency of each of the DCXs could be modulated to the corresponding resonant frequency, which could be different from the initially designed value. In addition, the pre-charge mode is investigated to make sure the system could start safely considering the high level and potential large inrush current without the addition of external hardware.

The success of such an XFC is not only determined by the power electronics design and control but also up to the interaction with the grid. This paper finds that such high power can cause the grid-voltage dip at some special moment and location. The proposed approach is to let the PFC stage generate reactive power to support the grid. Future work of this research is to test the system up to 1 MVA once the hardware is ready.

Author Contributions: Conceptualization, Z.L., D.M., H.B., and M.J.; methodology, Z.L. and M.J.; software, Z.L. and M.J.; validation, Z.L. and D.M.; formal analysis, D.M. and H.B.; investigation, Z.L. and M.J.; resources, H.B. and D.M.; writing - original draft preparation, Z.W., H.B., M.J., and D.M.; writing一review and editing, Z.L. and D.M.; supervision, H.B.; project administration, H.B.; funding acquisition, H.B. All authors have read and agreed to the published version of the manuscript.

Funding: This research was funded by ARPA-E CIRCUITS, grant number DE-AR0000901. 
Acknowledgments: Authors would like to thank for the support of ARPA-E CIRCUITS program. In addition, authors acknowledge the contribution of Wolfspeed, as the project lead, proposed the topology, constructed the hardware and provided HV SiC modules.

Conflicts of Interest: The authors declare no conflict of interest.

\section{Nomenclature}

The following abbreviations are used in this manuscript:

\begin{tabular}{|c|c|}
\hline $\mathrm{AC}$ & Alternating Current \\
\hline CCM & Continuous Conduction Mode \\
\hline$C_{r}$ & Resonant Capacitance \\
\hline $\mathrm{DAB}$ & Dual Active Bridge \\
\hline DC & Direct Current \\
\hline DCX & DC Transformer \\
\hline $\mathrm{DC} / \mathrm{DC}$ & $\mathrm{DC}$ to $\mathrm{DC}$ \\
\hline$d_{1}, d_{2}$ & Duty Cycles for PFC stage \\
\hline EMS & Energy Management System \\
\hline EV & Electric Vehicle \\
\hline FPGA & Field Programmable Gata Array \\
\hline$f_{r}$ & Resonant Frequency \\
\hline$f_{S}$ & Switching Frequency \\
\hline$f_{\text {initial }}$ & Initial working frequency \\
\hline$L_{r d}$ & Designed resonant inductance \\
\hline$C_{r d}$ & Designed resonant capacitance \\
\hline $\mathrm{HV}$ & High Voltage \\
\hline ISOP & Input Series Output Parallel \\
\hline$L_{r}$ & Resonant Inductance \\
\hline LVDC & Low-Voltage DC \\
\hline MOSFET & Metal Oxide Semiconductor Field Effect Transistor \\
\hline MTTF & Mean Time To Failure \\
\hline MV & Medium Voltage \\
\hline MW & Megawatt \\
\hline PFC & Power Factor Correction \\
\hline PWM & Pulse Width Modulation \\
\hline RMS & Root Mean Square \\
\hline$R_{1}, R_{2}$ & PFC Load Resistances \\
\hline $\mathrm{Si}$ & Silicon \\
\hline $\mathrm{SiC}$ & Silicon Carbide \\
\hline SOC & State of Charge \\
\hline$T_{\mathrm{s}}$ & Switching Period \\
\hline THD & Total Harmonic Distortion \\
\hline VAC & AC Voltage \\
\hline VAR & Reactive Power \\
\hline VDC & DC Voltage \\
\hline$V_{\text {in }}$ & Input Voltage \\
\hline$V_{o 1}, V_{o 2}$ & PFC Output Voltages \\
\hline$V_{\text {voa }}$ & Average Output Voltage \\
\hline WBG & Wide Bandgap \\
\hline $\mathrm{XFC}$ & Extreme Fast Charger \\
\hline XFMR & Transformer \\
\hline$\eta$ & Efficiency \\
\hline
\end{tabular}




\section{References}

1. Hajian, M.; Zareipour, H.; Rosehart, W.D. Environmental benefits of plug-in hybrid electric vehicles: The case of Alberta. In Proceedings of the 2009 IEEE Power \& Energy Society General Meeting, Calgary, AB, Canada, 26-30 July 2009; pp. 1-6.

2. Lulhe, A.M.; Date, T.N. A technology review paper for drives used in electrical vehicle (EV) \& hybrid electrical vehicles (HEV). In Proceedings of the 2015 International Conference on Control, Instrumentation, Communication and Computational Technologies (ICCICCT), Kumaracoil, India, 18-19 December 2015; pp. 632-636.

3. Ahmed, S.; Bloom, I.; Jansen, A.N.; Tanim, T.; Dufek, E.J.; Pesaran, A.; Burnham, A.; Carlson, R.B.; Dias, F.; Hardy, K.; et al. Enabling fast charging-A battery technology gap assessment. J. Power Sources 2017, 367, 250-262.

4. Tu, H.; Feng, H.; Srdic, S.; Lukic, S.M. Extreme Fast Charging of Electric Vehicles: A Technology Overview. IEEE Trans. Transp. Electrif. 2019, 5, 861-878. [CrossRef]

5. Ji, S.; Huang, X.; Zhang, L.; Palmer, J.; Giewont, W.; Wang, F.; Tolbert, L.M. Medium voltage (13.8 kV) transformer-less grid-connected DC/AC converter design and demonstration using $10 \mathrm{kV} \mathrm{SiC} \mathrm{MOSFETs.}$ In Proceedings of the 2019 IEEE Energy Conversion Congress and Exposition (ECCE), Baltimore, MD, USA, 29 September-3 October 2019; pp. 1953-1959.

6. Chow, T.P. Wide bandgap semiconductor power devices for energy efficient systems. In Proceedings of the 2015 IEEE 3rd Workshop on Wide Bandgap Power Devices and Applications (WiPDA), Blacksburg, VA, USA, 2-4 November 2015; pp. 402-405.

7. Armstrong, K.O.; Das, S.; Cresko, J. Wide bandgap semiconductor opportunities in power electronics. In Proceedings of the 2016 IEEE 4th Workshop on Wide Bandgap Power Devices and Applications (WiPDA), Fayetteville, AR, USA, 7-9 November 2016.

8. Zhao, B.; Song, Q.; Liu, W.; Sun, Y. Overview of dual-active-bridge isolated bidirectional DC-DC converter for high-frequency-link power-conversion system. IEEE Trans. Power Electron. 2014, 29, 4091-4106. [CrossRef]

9. Wen, H.; Gong, J.; Yeh, C.-S.; Han, Y.; Lai, J. An investigation on fully zero-voltage-switching condition for high-frequency GaN based LLC converter in solid-state-transformer application. In Proceedings of the 2019 IEEE Applied Power Electronics Conference and Exposition (APEC), Anaheim, CA, USA, 17-21 March 2019; pp. 797-801.

10. Li, B.; Li, Q.; Lee, F.C. A WBG based three phase $12.5 \mathrm{~kW} 500 \mathrm{kHz}$ CLLC resonant converter with integrated PCB winding transformer. In Proceedings of the 2018 IEEE Applied Power Electronics Conference and Exposition (APEC), San Antonio, TX, USA, 4-8 March 2018; pp. 469-475.

11. Everts, J.; Krismer, F.; Keybus, J.V.D.; Driesen, J.; Kolar, J.W. Optimal ZVS modulation of single-phase single-stage bidirectional DAB AC-DC converters. IEEE Trans. Power Electron. 2013, 29, 3954-3970. [CrossRef]

12. Khalid, U.; Shu, D.; Wang, H. Hybrid modulated reconfigurable bidirectional CLLC converter for V2G enabled PEV charging applications. In Proceedings of the 2019 IEEE Applied Power Electronics Conference and Exposition (APEC), Anaheim, CA, USA, 17-21 March 2019; pp. 3332-3338.

13. Singh, B.; Chandra, A.; Al-Haddad, K.; Pandey, A.; Kothari, D.P. A review of single-phase improved power quality ac dc converters. IEEE Trans. Ind. Electron. 2003, 50, 962-981. [CrossRef]

14. Jovanovic, M.; Jang, Y. State-of-the-art, single-phase, active power-factor-correction techniques for high-power applications-an overview. IEEE Trans. Ind. Electron. 2005, 52, 701-708. [CrossRef]

15. Sankar, U.A.; Mishra, S.; Viswanathan, K.; Naik, R. Control of a series input boost pre-regulator with unbalanced load. In Proceedings of the IECON 2014 - 40th Annual Conference of the IEEE Industrial Electronics Society, Dallas, TX, USA, 29 October-1 November 2014; pp. 4582-4588.

16. Mukhopadhyay, A.; Mishra, S. FPGA based novel voltage balancing technique for series input boost pre-regulator. In Proceedings of the IECON 2017 - 43rd Annual Conference of the IEEE Industrial Electronics Society, Beijing, China, 29 October-1 November 2017; pp. 1160-1165.

17. Li, H.; Jiang, Z. On automatic resonant frequency tracking in LLC series resonant converter based on zero-current duration time of secondary diode. IEEE Trans. Power Electron. 2015, 31, 4956-4962. [CrossRef]

18. Kundu, U.; Chakraborty, S.; Sensarma, P. Automatic resonant frequency tracking in parallel LLC boost DC-DC converter. IEEE Trans. Power Electron. 2014, 30, 3925-3933. [CrossRef] 
19. Yang, X.; Chen, H.; Shi, J.; Hu, W.; Wang, L.; Liu, J.; Hu, P.; Xiaonan, Y.; Hongkun, C.; Jing, S.; et al. A novel precharge control strategy for modular multilevel converter. In Proceedings of the 2015 IEEE PES Asia-Pacific Power and Energy Engineering Conference (APPEEC), Brisbane, QLD, Australia, 15-18 November 2015; pp. 1-5.

20. Deng, Q.; Tripathy, S.; Tylavsky, D.; Stowers, T.; Loehr, J. Demand Modeling of a dc Fast Charging Station. In Proceedings of the 2018 North American Power Symposium (NAPS), Fargo, ND, USA, 9-11 September 2018; pp. 1-6.

(C) 2020 by the authors. Licensee MDPI, Basel, Switzerland. This article is an open access article distributed under the terms and conditions of the Creative Commons Attribution (CC BY) license (http://creativecommons.org/licenses/by/4.0/). 